\title{
Phytochemicals from Lauraceae Species
}

\author{
A. Hamid A.Hadi ${ }^{*}$ \\ Department of Chemistry, Faculty of Science, University of Malaya, Kuala Lumpur, Malaysia; \\ E-mail: ahamid@um.edu.my
}

The family of Lauraceae comprising a group of flowering plants contains about 55 genera and over 2,000 species worldwide. In Malaysia there are 213 species of Lauraceae known as medang or tejur. Studies on these plant species resulted in various type of compounds such as alkaloid, flavonoids, chalcone, terpenoid and simple aromatic compounds. Some these of compounds have shown biological activity such as antimicrobial, antiplasmodium and anticancer. This paper describes the phytochemicals and some biological activity of isolated compounds from Lauraceae species.

Keywords: Lauraceae, phtochemicals, biological activity. 